\title{
Direct and semi-direct impacts of absorbing biomass burning aerosol on the climate of southern Africa: a Geophysical Fluid Dynamics Laboratory GCM sensitivity study
}

\author{
C. A. Randles ${ }^{1, *}$ and V. Ramaswamy ${ }^{1,2}$ \\ ${ }^{1}$ Atmospheric and Oceanic Sciences Program, Princeton University, Princeton, New Jersey, USA \\ ${ }^{2}$ NOAA Geophysical Fluid Dynamics Laboratory, Princeton, New Jersey, USA \\ "now at: Goddard Earth Sciences and Technology Center, University of Maryland, Baltimore County and NASA GSFC Code \\ 613.3, Greenbelt, Maryland, USA
}

Received: 19 February 2010 - Published in Atmos. Chem. Phys. Discuss.: 16 April 2010

Revised: 20 August 2010 - Accepted: 4 October 2010 - Published: 19 October 2010

\begin{abstract}
Tropospheric aerosols emitted from biomass burning reduce solar radiation at the surface and locally heat the atmosphere. Equilibrium simulations using an atmospheric general circulation model (GFDL AGCM) indicate that strong atmospheric absorption from these particles can cool the surface and increase upward motion and low-level convergence over southern Africa during the dry season. These changes increase sea level pressure over land in the biomass burning region and spin-up the hydrologic cycle by increasing clouds, atmospheric water vapor, and, to a lesser extent, precipitation. Cloud increases serve to reinforce the surface radiative cooling tendency of the aerosol. Conversely, if the climate over southern Africa were hypothetically forced by high loadings of scattering aerosol, then the change in the low-level circulation and increased subsidence would serve to decrease clouds, precipitation, and atmospheric water vapor. Surface cooling associated with scattering-only aerosols is mitigated by warming from cloud decreases. The direct and semi-direct climate impacts of biomass burning aerosol over southern Africa are sensitive to the total amount of aerosol absorption and how clouds change in response to the aerosol-induced heating of the atmosphere.
\end{abstract}

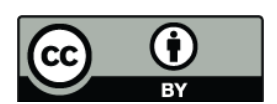

Correspondence to: C. A. Randles (crandles@umbc.edu)

\section{Introduction}

Biomass burning is a significant source of tropospheric aerosols in southern Africa during the dry season (AugustOctober or ASO). These carbonaceous particles extinguish the amount of sunlight reaching the Earth's surface, and their absorbing black carbon (BC) component heats the atmosphere aloft. By directly redistributing solar heating between the atmosphere and surface, $\mathrm{BC}$ aerosols can impact atmospheric stability, regional circulation patterns, and the hydrologic cycle (Ramanathan and Carmichael, 2008).

The IPCC estimates the direct radiative forcing of biomass burning (bb) aerosol to be $+0.03 \pm 0.12 \mathrm{~W} \mathrm{~m}^{-2}$ on the global, annual average (Solomon et al., 2007); however, it can be much greater than that of greenhouse gasses (GHGs) on local and regional scales (e.g. Keil and Haywood, 2003). Much of the uncertainty in bb aerosol radiative forcing results from uncertainties in (1) the aerosol optical properties, (2) the spatial distribution of the aerosol in both the horizontal and vertical (e.g. Haywood and Ramaswamy, 1998), (3) the amount of biomass burning aerosol, and (4) the presence of absorbing aerosol above highly reflective surfaces such as clouds (e.g. Chýlek and Coakley, 1974). There is even greater uncertainty involved when trying to determine the response of the climate and the hydrologic cycle to bb aerosol forcing. For example, microphysical interactions between aerosols and clouds may impact precipitation formation processes through the aerosol indirect effect.

Besides microphysical impacts of bb aerosol on the hydrologic cycle (indirect effect), because bb aerosol are absorbing, they can also impact clouds through the semidirect effect. Originally the semi-direct effect referred to

Published by Copernicus Publications on behalf of the European Geosciences Union. 
the evaporation of low clouds due to shortwave aerosol heating (Hansen et al., 1997). The loss of clouds was shown to exacerbate the positive forcing (warming effect) of absorbing aerosols on the climate. Since the Hansen et al. (1997) study, however, numerous studies, both observationally- and model-based, have shown that the sign of the semi-direct effect can range from positive to negative (i.e. warming to cooling) depending on if low-level clouds are reduced or enhanced, respectively. Using satellite data from MODIS, Koren et al. (2004) demonstrated that bb smoke in the Amazon stabilized the boundary layer and reduced convective activity and boundary layer cloud formation. Conversely, Brioude et al. (2009) used cloud observations from GOES and MODIS combined with bb aerosol from the FLEXPART model to show that bb aerosol over marine stratocumulus off the coast of California enhanced cloud cover, particularly when humidity was high. In a large-eddy simulation (LES) study, Johnson et al. (2004) showed that shortwave atmospheric heating by absorbing aerosol in the boundary layer may increase evaporation in cloud drops and reduce lowlevel clouds and precipitation while increasing column stability. However, when absorbing aerosol are located above the boundary layer, a negative (cooling) semi-direct results due to a decreased entrainment rate that increases liquid water path in the boundary layer and clouds.

GCM studies of the direct and semi-direct effects of absorbing aerosols over northern Africa and the Indian monsoon region have found that widespread regional aerosol atmospheric heating may induce rising motion and low-level moisture convergence that increases clouds, rainfall, and latent heating, the latter of which excites positive feedback processes (e.g. Miller et al., 2004; Lau et al., 2006; Randles and Ramaswamy, 2008 (hereafter RR08), Lau et al. 2009). This increased rainfall, however, may be tempered or even eliminated once the aerosol surface radiative cooling tendency is manifest in sea surface temperature (SST) tendencies (e.g. Ramanathan et al., 2005; Ramanathan and Charmichael, 2008). From these and other studies, it is apparent that the aerosol semi-direct effect can vary in sign from positive (decreased cloud cover and warming) to negative (increased cloud cover and cooling) depending on the region and conditions considered. Koch and del Genio (2010) provide a thorough review of the many disparate findings with regards to aerosol absorption effects on clouds.

Many studies have focused on quantifying the optical properties of and radiative forcing due to bb aerosols over southern Africa (e.g. Myhre et al., 2003; Abel et al., 2005), with widely ranging estimates of top-of-the-atmosphere (TOA), atmospheric (ATM) and surface (SFC) radiative forcing. Fewer studies have examined the climate response of the African region to bb aerosol forcing. Paeth and Feichter (2006) used equilibrium simulations in the ECHAM4 GCM to de-convolve the influences of GHGs and bb aerosol on climate. While GHG warming tended to dominate the surface air temperature response, they found that aerosol in- duced solar flux reductions to the surface contributed to an overall decrease in sensible and latent heat fluxes and precipitation in southern Africa. In contrast, using transient simulations in the Max Planck Institute Earth System Model (MPIESM), a fully coupled atmosphere-ocean GCM with interactive aerosols, Roeckner et al. (2006) found that GHG induced surface air warming over central Africa was largely compensated by bb aerosol cooling. Also, increased atmospheric absorption from larger increases in carbonaceous aerosols contributed to circulation changes that favored the transport of moisture from the Atlantic Ocean into southern Africa. These circulation changes contributed to a positive impact on the overall precipitation trend and increased soil moisture, liquid water path, and clouds. Though the results of these studies differ, they each demonstrate that the direct and semi-direct effects of absorbing bb aerosols likely impact climate in a significant manner in southern Africa.

In the present study, using an atmospheric general circulation model (AGCM), we investigate the sensitivity of the climate impacts by considering a range in bb aerosol optical properties, namely the aerosol optical depth (AOD) and the aerosol absorption optical depth (AAOD), and, by extension, the aerosol single scattering albedo (SSA). We expect that in doing so, we will also obtain a wider range in model climate response that will offer additional perspectives on the direct and semi-direct impacts of absorbing bb aerosols on the hydrologic cycle over southern Africa. We incorporate satellite and in situ measurements of two key aerosol optical properties at $500 \mathrm{~nm}$, the AOD and SSA, into some of these sensitivity experiments in an attempt to systematically bound the aerosol optical properties in the model. We also consider a purely hypothetical case of scattering-only aerosols to emphasize the role of aerosol absorption on the climate response.

Our analysis is focused on the response of the southern African climate to bb aerosol direct and semi-direct effects only, given that these aerosols are a significant part of the column burden and thus are likely to be a major aerosol player in the region. We do not consider the aerosol indirect effect in this study; this assumption seems reasonable since relative humidity is so low in austral winter that indirect aerosol effects are expected to be minimal compared to the direct and semi-direct aerosol effects (Swap et al., 2003). Special emphasis is placed on surface air temperature and hydrologic cycle responses.

\section{Model description and experimental design}

The analysis is based on experiments performed with the Geophysical Fluid Dynamics Laboratory's (GFDL) atmospheric-land GCM AM2-LM2 (Anderson et al., 2004) set to $\mathrm{N} 45$ resolution $\left(2.5^{\circ}\right.$ longitude $\times 2.0^{\circ}$ latitude with 24 vertical levels). Ginoux et al. (2006) describe the treatment and evaluation of aerosols in the GCM. Briefly, 
Table 1. Experimental Design. All experiments have the same natural (sea salt plus dust) and sulfate $\left(\mathrm{SO}_{4}\right)$ distributions from $\mathrm{MOZART}-2$ (Horowitz, 2006). Experiments differ based solely on the prescription of OC and BC distributions. All other forcing agents (e.g. long-lived greenhouse gasses, prescribed observed sea surface temperatures) are held constant. Differencing an experiment with respect to the CTRL case indicates the response of the model to biomass burning aerosol forcing.

\begin{tabular}{lll}
\hline Experiment & Natural Aerosols and $\mathrm{SO}_{4}$ & Biomass Burning (BC and OC) aerosols \\
\hline CTRL & MOZART-2 Y2000 & None \\
MOZEX & MOZART-2 Y2000 & MOZART-2 Y2000 \\
HIGHEX & MOZART-2 Y2000 & MOZART-2 Y2000 adjusted below $\sim 4 \mathrm{~km}$ \\
& & to mimic total aerosol AOD in Fig. 1a; \\
& & $\sim$ same SSA as MOZEX (Fig. 1f) \\
SSAEX & MOZART-2 Y2000 & $\begin{array}{l}\text { MOZART-2 Y2000 adjusted below } \sim 4 \mathrm{~km} \\
\text { to mimic total aerosol AOD and SSA in }\end{array}$ \\
& & Figs. 1a and c. \\
WHITE & MOZART-2 Y2000 & Same as HIGHEX but optical properties of \\
& & OC and BC treated as dry sulfate. \\
\hline
\end{tabular}

three-dimensional monthly-mean mass profiles of five externally-mixed aerosol species (sulfate $\left(\mathrm{SO}_{4}\right), \mathrm{BC}$, organic carbon (OC), dust (DU), and sea salt (SS)) are simulated offline with a chemical transport model and prescribed (linearly interpolated between months). Optical properties for each species are determined offline as a function of wavelength and relative humidity using Mie theory and assumed aerosol physical and optical properties (Haywood and Ramaswamy, 1998; Haywood et al., 1999).

AM2-LM2 includes the direct and semi-direct aerosol effects only (i.e. aerosols impact radiative fluxes); interactions between aerosols and cloud microphysics are not considered. The total aerosol optical properties are calculated as a function of wavelength $(\lambda)$ and relative humidity $(\mathrm{RH})$ according to Eqs. (1) and (2):

$$
\begin{aligned}
\operatorname{AOD}(\lambda)= & \sum_{z}\left(M_{\mathrm{BC}} \sigma_{\mathrm{BC}}+M_{\mathrm{OC}} \sigma_{\mathrm{OC}} f_{\mathrm{OC}}(\mathrm{RH})+\right. \\
& M_{\mathrm{SO}_{4}} \sigma_{\mathrm{SO}_{4}} f_{\mathrm{SO}_{4}}(\mathrm{RH})+M_{\mathrm{DU}} \sigma_{\mathrm{DU}}+ \\
& \left.M_{\mathrm{SS}} \sigma_{\mathrm{SS}} f_{\mathrm{SS}}(\mathrm{RH})\right)
\end{aligned}
$$

$$
\begin{aligned}
\operatorname{AAOD}(\lambda)= & \sum_{z}\left(M_{\mathrm{BC}} \sigma_{\mathrm{BC}} \tilde{\omega}_{\mathrm{BC}}+\right. \\
& M_{\mathrm{OC}} \sigma_{\mathrm{OC}} f_{\mathrm{OC}}(\mathrm{RH}) \tilde{\omega}_{\mathrm{OC}}(\mathrm{RH})+ \\
& M_{\mathrm{SO}_{4}} \sigma_{\mathrm{SO}_{4}} f_{\mathrm{SO}_{4}}(\mathrm{RH}) \tilde{\omega}_{\mathrm{SO}_{4}}(\mathrm{RH})+ \\
& M_{\mathrm{DU}} \sigma_{\mathrm{DU}} \tilde{\omega}_{\mathrm{DU}}+ \\
& \left.M_{\mathrm{SS}} \sigma_{\mathrm{SS}} f_{\mathrm{SS}}(\mathrm{RH}) \tilde{\omega}_{\mathrm{SS}}(\mathrm{RH})\right)
\end{aligned}
$$

where $M$ refers to aerosol mass $\left[\mathrm{g} \mathrm{m}^{-2}\right]$ in a grid box, $\sigma$ to the mass extinction efficiency $\left[\mathrm{m}^{2} \mathrm{~g}^{-1}\right], f(\mathrm{RH})$ to the variation of $\sigma$ with $\mathrm{RH}$, and $\tilde{\omega}$ to the single scattering coalbedo $(\tilde{\omega}=1-\mathrm{SSA})$, which may also vary with RH depending on the aerosol component. The optical effects of hygroscopic growth with changing model $\mathrm{RH}$ are considered for sea salt and sulfate aerosols. For this study, the optical properties of OC aerosols are modified to allow for mild absorption and hygroscopic growth following Ming et al. (2005) to be consistent with observations of bb aerosol hygroscopic growth from the southern African SAFARI 2000 field campaign (Magi et al., 2003).

Our experimental design is similar to Menon et al. (2002) and RR08, and it aims to isolate the climate response to bb aerosol direct and semi-direct effects only by considering a range of bb aerosol optical properties. We conduct one control experiment and four sensitivity experiments, all of which share the same present-day climatological observed SSTs (Reynolds et al., 2002), sea-ice, long-lived GHGs, ozone, land-surface properties, and natural (dust plus sea salt) and sulfate aerosols. We run each equilibrium simulation for 35 years, analyze the results from the last 30 years of each simulation, and determine significance using a two-tailed students t-test as in RR08. Table 1 summarizes the prescription of aerosol mass for each experiment, and the area-averaged aerosol optical properties and carbonaceous aerosol (BC plus OC) mass loadings are given in Table 2.

In making the choice that only carbonaceous aerosols differ between the control experiment and the sensitivity experiments, we have implicitly assumed that the majority of bb aerosol direct and semi-direct forcing is due primarily to carbonaceous aerosol. This assumption is supported by Magi (2009), which found on the basis of data collected during SAFARI 2000 that organic matter $(\mathrm{OM}=1.4 \times \mathrm{OC})$ and $\mathrm{BC}$ accounted for $27 \%$ and $73 \%$ of aerosol absorption, respectively, and $90 \%$ of the scattering in the tropics of southern Africa. Magi (2009) also show that carbonaceous aerosol comprised $83 \%$ and $54 \%$ of the $\mathrm{PM}_{2.5}$ in the tropics and extratropics of southern Africa, respectively. We note that the Model of OZone And Related chemical Tracers version 2 (MOZART-2) aerosol distributions of $\mathrm{SO}_{4}, \mathrm{OC}$, and $\mathrm{BC}$ (Horowitz, 2006) used in this 

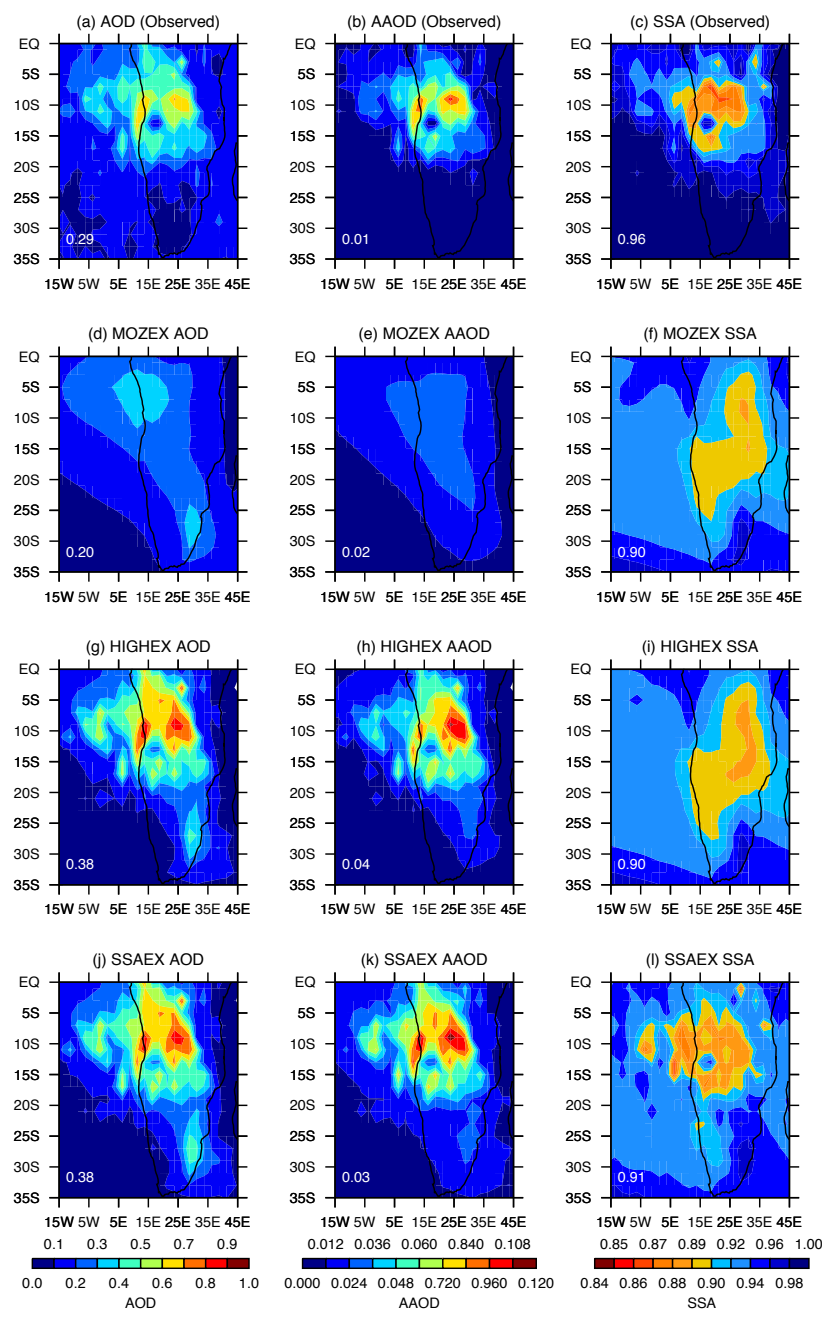

Fig. 1. ASO aerosol optical depth (AOD; left column), aerosol absorption optical depth (AAOD; center column), and single scattering albedo (SSA; right column) based on observations from AERONET and EP-TOMS (a-c), and for MOZEX (d-f), HIGHEX $(\mathbf{g}-\mathbf{i})$, and SSAEX $(\mathbf{j}-\mathbf{l})$. Recall that HIGHEX, SSAEX, and WHITE (not shown) have similar aerosol mass distributions, so (g) and $(j)$ are nearly the same. MOZEX and HIGHEX have the same $\mathrm{OC} / \mathrm{BC}$ mass ratio, so the single scattering albedos in (f) and (i) are also similar. Differences arise due to changes in relative humidity in each experiment, as described in the text. Land area-averaged $\left(3^{\circ} \mathrm{N}-37^{\circ} \mathrm{S}, 19^{\circ} \mathrm{W}-50^{\circ} \mathrm{E}\right)$ optical properties are given in the lower left of each panel. Note that the optical properties here are for the total aerosol, which includes not only bb aerosols (OC plus BC), but also sulfate $\left(\mathrm{SO}_{4}\right)$, sea salt, and dust.

study include aerosols emitted from both biomass burning and anthropogenic sources (e.g. fossil fuels). We therefore are also assuming that the anthropogenic contribution to aerosol mass in the region is well represented by MOZART2 .
In the control experiment (CTRL), we prescribe natural (dust plus sea salt) and sulfate aerosol distributions simulated by MOZART-2 (Horowitz, 2006) for the year 2000; no carbonaceous aerosols are prescribed in CTRL. In the base case experiment MOZEX, we also include BC and OC aerosols from MOZART-2. The aerosol distributions from MOZART2 (and MOZEX) are the same as those used as forcing agents for the GFDL coupled climate model (CM2.1) simulations reported in the IPCC Fourth Assessment Report (AR4) (Delworth et al., 2006). Ginoux et al. (2006) and Magi et al. (2009) both found that in biomass burning regions, modeled AOD in AM2-LM2 tended to be biased low relative to observations from the ground-based AEROsol robotics NETwork (AERONET) (Holben et al., 2001) and retrievals from the NASA MODIS satellite (Kaufman et al., 1997). Discrepancies between modeled (low-biased) AOD and (highbiased) SSA relative to observations are minimized in AM2LM2 by increasing OC and BC emissions by factors of 1.6 and 1.8, respectively (Magi et al., 2009).

Motivated by the demonstrated underestimate in AOD and aerosol absorption in the model (MOZEX) over southern Africa (Ginoux et al., 2006; Magi et al., 2009), for use in the remaining three experiments, we combined daily observations of AOD and SSA from AERONET and the EP-TOMS instrument (Torres et al., 2005) into monthly-mean gridded maps (Fig. $1 \mathrm{a}-\mathrm{c})$. Note that AAOD $=$ AOD $\times(1-\mathrm{SSA})$. We chose to use data from EP-TOMS because, to our knowledge, it is the only observational dataset that provides global horizontal distributions of both AOD and SSA over land and ocean.

AOD and SSA are derived from EP-TOMS retrievals using the near-UV retrieval method (Torres et al. 1998; 2002; 2005). This method uses the ratio of backscattered radiances at two measured UV wavelengths (330 and $380 \mathrm{~nm}$ ) in an inversion procedure that employs a pre-compiled set of lookup tables (LUTs). The LUTs are generated using a radiative transfer code that assumes aerosol models based on a combination of spectral and geographical location considerations (based on emission characteristics) to determine AOD and SSA. Retrieved AOD and SSA are reported at $380 \mathrm{~nm}$ and interpolated to $500 \mathrm{~nm}$ using the LUTs. Sources of uncertainty in the EP-TOMS retrievals include the assumed aerosol vertical distribution and sub-pixel cloud contamination effects resulting from the wide field of view $(40 \times 40$ $\mathrm{km}^{2}$ at nadir and as large as $200 \times 200 \mathrm{~km}^{2}$ at extreme offnadir viewing geometry). Overestimates by EP-TOMS occur when extinction optical depths are below 0.2 because the coarse resolution of the EP-TOMS product makes it difficult to resolve small-scale variability. Other sources of uncertainty in the EP-TOMS retrieval algorithm include aerosol vertical distributions, sub-pixel cloud contamination effects, and the surface reflectivity (Torres et al., 2005). However, the advantages of the near-UV retrieval method are the ability to retrieve aerosol properties over most terrestrial surfaces including deserts and a low sensitivity to particle 
Table 2. Land area-averaged ( $\left.3^{\circ} \mathrm{N}-37^{\circ} \mathrm{S}, 19^{\circ} \mathrm{W}-50^{\circ} \mathrm{E}\right)$ aerosol optical depth (AOD), aerosol absorption optical depth (AAOD), and single scattering albedo (SSA) for each experiment and the EP-TOMS/AERONET observationally-based maps from Figure 1 a-c (Observed). Here $\mathrm{AAOD}=\mathrm{AOD} \times(1-\mathrm{SSA})$. Land area-averages for the main biomass burning region $\left(7^{\circ} \mathrm{S}-17^{\circ} \mathrm{S}, 11^{\circ} \mathrm{E}-29^{\circ} \mathrm{E}\right)$ are given in parenthesis. ASO total mass loading of $\mathrm{BC}$ and $\mathrm{OC}$ for each experiment over land for the entire region $\left(3^{\circ} \mathrm{N}-37^{\circ} \mathrm{S}, 19^{\circ} \mathrm{W}-50^{\circ} \mathrm{E}\right)$ is also given. Recall that CTRL does not have $\mathrm{BC}$ or OC.

\begin{tabular}{lrrrrr}
\hline Experiment & AOD & AAOD & SSA & OC $[\mathrm{Mg}]$ & BC $[\mathrm{Mg}]$ \\
\hline Observed & $0.29(0.46)$ & $0.012(0.041)$ & $0.96(0.91)$ & - & - \\
CTRL & $0.1(0.1)$ & $0.003(0.004)$ & $0.97(0.96)$ & - & - \\
MOZEX & $0.20(0.25)$ & $0.020(0.028)$ & $0.90(0.89)$ & 128.0 & 19.6 \\
HIGHEX & $0.38(0.66)$ & $0.038(0.079)$ & $0.90(0.88)$ & 312.1 & 41.0 \\
SSAEX & $0.38(0.66)$ & $0.034(0.073)$ & $0.91(0.89)$ & 330.3 & 36.9 \\
WHITE & $0.38(0.65)$ & $0.004(0.007)$ & $0.99(0.99)$ & 312.1 & 41.0 \\
\hline
\end{tabular}

shape (Torres et al., 2002). During SAFARI 2000, Torres et al. (2005) performed an extensive validation of EP-TOMS relative to AERONET at high time- and spatial- resolution and found that AOD and SSA were generally within the observational uncertainty of AERONET $( \pm 30 \%$ for AOD and \pm 0.03 for SSA).

In constructing the maps (Fig. 1a-c), daily-mean gridded $\left(1^{\circ} \times 1^{\circ}\right)$ retrievals of AOD and SSA from EP-TOMS were aggregated to the $2^{\circ} \times 2.5^{\circ}$ model grid. Then, if a grid box did not contain an EP-TOMS retrieval for a particular day and if the grid box was co-located with one of 18 AERONET sites in southern Africa during 2000 (see supplemental material for a listing of sites used), we assigned the grid box the dailyaveraged Level 2.0, Version 2.0 AERONET observation of AOD and SSA at $500 \mathrm{~nm}$, if available. Grid boxes with missing data were then linearly interpolated from nearestneighbor grid boxes. Daily-mean gridded maps were then averaged to monthly-mean maps. We acknowledge that our gap-filling method may tend to bias the aerosol optical properties in a grid box containing a station to the AERONET retrieved AOD, rather than those from EP-TOMS. The SSA tends to be less biased towards the AERONET retrievals because the are far fewer retrievals of SSA from AERONET (see supplemental material). However, it is important to emphasize that in this sensitivity study, these maps are used only as a guide to design experiments that are more similar to available observations than MOZEX. This is similar to the approach used in Abel et al. (2005) in which MODIS and AERONET retrievals of AOD were used to scale modeled aerosol optical properties for forcing calculations. Because our aim in using these maps is simply to help define a reasonable parameter space for the aerosol optical properties, it is beyond the scope of this study to do a detailed comparison of EP-TOMS and AERONET retrievals of AOD and SSA, and we refer the reader to Torres et al. (2005) for a more detailed comparison of AERONET and EP-TOMS retrieved aerosol optical properties during SAFARI 2000.
Figure 1 compares the $500 \mathrm{~nm}$ AOD, AAOD, and SSA using the observations (Fig. 1a-c) and for the four experiments (Fig. 1d-1) during the biomass burning season (ASO). Figure 2 shows the carbonaceous aerosol column load for each experiment. In constructing experiments HIGHEX and SSAEX Equations (1) and (2) were solved for $M_{B C}$ and $M_{\mathrm{OC}}$ at $500 \mathrm{~nm}$ assuming that the dust, sea-salt, and sulfate mass were the same as in CTRL and MOZEX. The total aerosol AOD and AAOD (left hand side of Eq. 1 and 2) were from MOZEX or from Fig. 1a-c, depending on the experiment as described below. We also assumed that the RH was the 30year mean from MOZEX; therefore $f(\mathrm{RH})$ and $\tilde{\omega}(\mathrm{RH})$ were fixed to a single value for each aerosol constituent. These assumptions allowed us to solve Eqs. (1) and (2); however, in a mass-based aerosol model it is difficult to constrain aerosol optical properties exactly because of non-linearities associated with aerosol hygroscopic growth. The assumption of MOZEX RH has consequences for the optical properties of HIGHEX and SSAEX if the RH in these experiments differs from the 30-year MOZEX average; an overestimation or underestimation of AOD compared to the observations may occur if the model relative humidity in a given sensitivity experiment is higher or lower than in MOZEX, respectively. However, since our purpose in this sensitivity study is to try and widely bound the real world in terms of aerosol optical properties, and as our results will show, in the context of this global model study it is not necessary that we precisely mimic observations, which have their own uncertainties.

In experiment HIGHEX, BC and OC distributions from MOZART-2 are scaled-up in proportion below $\sim 4 \mathrm{~km}$ over southern Africa so that AOD roughly agrees with our observationally-based map (Fig. 1a) while the SSA is roughly the same as in MOZEX (Fig. 1f). We only alter the bb aerosol distributions below $\sim 4 \mathrm{~km}$ because boundarylayer (BL) height in southern Africa typically reaches this altitude in the early afternoon, and during SAFARI 2000, bb aerosol tended to be well mixed in the BL over land due to strong dry convection (Haywood et al., 2003). In addition, 


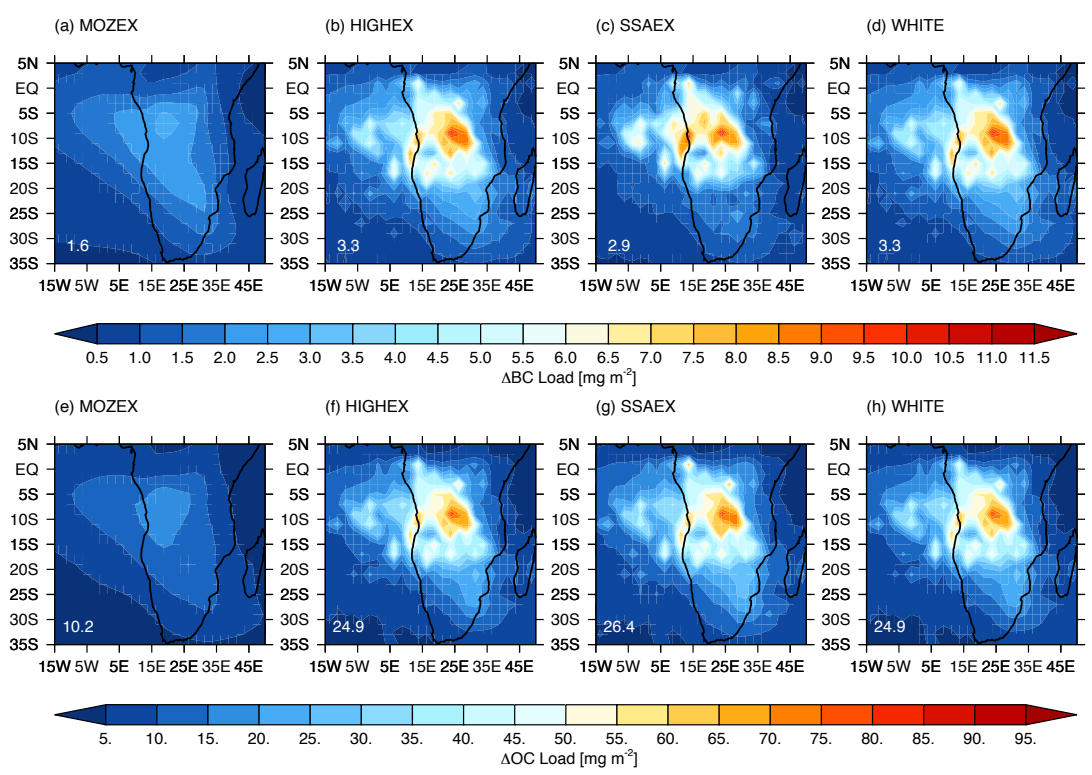

Fig. 2. ASO black carbon (BC) column load $\left[\mathrm{mg} \mathrm{m}^{-3}\right.$ ] for (a) MOZEX, (b) HIGHEX, (c) SSAEX, and (d) WHITE. ASO organic carbon (OC) column load $\left[\mathrm{mg} \mathrm{m}^{-3}\right.$ ] for (e) MOZEX, (f) HIGHEX, (g) SSAEX, and (h) WHITE. Note that HIGHEX and WHITE have the same $\mathrm{BC}$ and $\mathrm{OC}$ distributions, but in WHITE both BC and OC are treated optically as scattering-only aerosols as described in the text. Land-area average column load is given in the bottom left of each panel for the region $\left(3^{\circ} \mathrm{N}-37^{\circ} \mathrm{S}, 19^{\circ} \mathrm{W}-50^{\circ} \mathrm{E}\right)$.

MOZART-2 tends to overestimate the amount of $\mathrm{BC}$ relative to in situ observations above about 400 to $600 \mathrm{hPa}$ (Koch et al., 2009). Thus, scaling up carbonaceous aerosol masses above this altitude would have exacerbated the positive bias in $\mathrm{BC}$, and therefore aerosol heating, aloft.

In experiment SSAEX, OC and BC are also scaled up below $\sim 4 \mathrm{~km}$ to agree roughly with the AOD in Fig. 1a. In addition, the proportion of $\mathrm{OC}$ to $\mathrm{BC}$ below $\sim 4 \mathrm{~km}$ is altered so that the SSA is similar to the observations (Fig. 1c). Total BC mass from MOZEX is roughly doubled in HIGEX and SSAEX, and OC mass increases by roughly a factor of 2.5 (Table 2, Fig. 2). Our final experiment WHITE has the same OC and BC mass distributions as HIGHEX (Fig. 2), but the optical properties of $\mathrm{BC}$ and $\mathrm{OC}$ are artificially set to be scattering-only such that SSA $\sim 1$ (deviation from 1 due to presence of some absorbing dust; not shown). The main aim for this purely hypothetical experiment is to flush out the contrasts with the experiments with increased absorbing bb aerosols (MOZEX, HIGHEX, SSAEX) and thus more clearly delineate their role.

Comparing the observationally-based map of SSA in Fig. 1c to the experiments, we see that outside the primary biomass burning region $\left(\sim 7^{\circ} \mathrm{S}-17^{\circ} \mathrm{S}, 11^{\circ} \mathrm{E}-29^{\circ} \mathrm{E}\right)$ the observed SSA is higher (less absorbing) than in the sensitivity experiments. This could be due to the fact that EP-TOMS tends to overestimate AOD below 0.2 (Torres et al., 2005). Indeed, the observed AODs over the oceans in Fig. 1a tend to be larger than modeled (particularly south of $17^{\circ} \mathrm{S}$ ). Over the oceans where scattering sea salt aerosol is more prevalent, higher AODs would have the effect of increasing SSA (decreasing the proportion of absorption). Alternatively, the model could have underestimated the contribution of sea salt aerosol to the AOD and SSA in this region. The model simulations predict higher AOD than observed in the industrial Highveld region of South Africa $\left(\sim 26^{\circ} \mathrm{S}, 28^{\circ} \mathrm{E}\right)$ where there is a large industrial sulfate source (recall, all simulations have the same sulfate mass distributions). This could indicate that the model sulfate is too high here, which could also be the case in other parts of the region and would have consequences for the total aerosol SSA, which depends on all aerosol constituents.

Figure 3 shows a comparison of monthly mean modeled and observed climatological AOD at four AERONET stations. In MOZEX, AOD is clearly underestimated and biomass burning tends to peak is October rather than in September as observed. By applying the scaling as described, we necessarily improve agreement between the model and observations of AOD, particularly in the biomass burning season. The climatological mean and standard deviation of ASO SSA from AERONET four these for stations (Mongu, Senanga, Skukuza, and Inhaca) are 0.84 \pm 0.03 , $0.85 \pm 0.02,0.88 \pm 0.04$, and $0.87 \pm 0.04$. (See supplemental material for SSA at other stations). In the grid boxes containing Mongu and Senanga, all experiments except WHITE have an SSA 0.88. MOZEX and HIGHEX have an SSA of 0.91 and 0.93 at Skukuza and Inhaca, respecitvely, while SSAEX has single scattering albedos of $\sim 0.94$ in these grid boxes. 

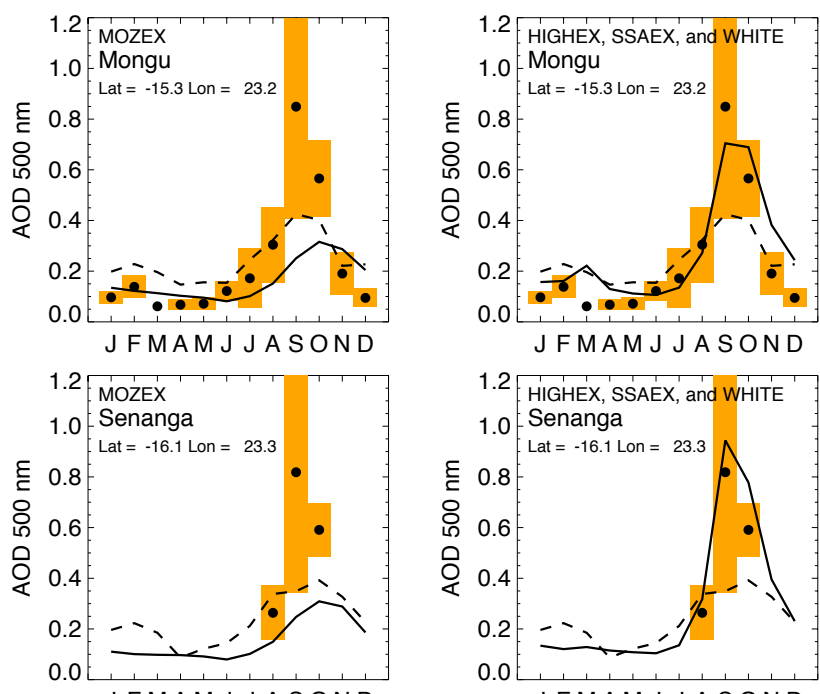

J FMAM J J A SOND
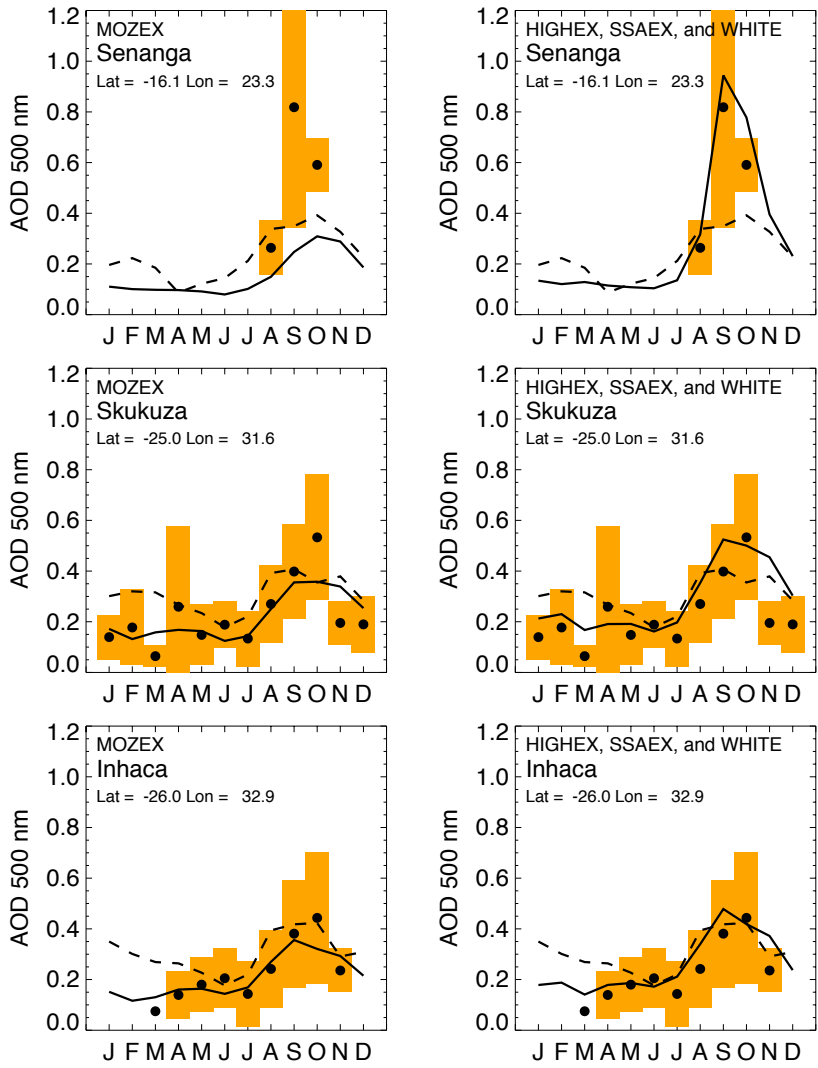

may be more appropriate to model their optical properties as those of regional haze rather than those of fresh fires that had SSAs closer to the AERONET measurements and the Leahy et al. (2007) estimate.

\section{Results}

In the following analysis, we focus on differences between the response of each experiment and the CTRL experiment over southern Africa $\left(3^{\circ} \mathrm{N}-37^{\circ} \mathrm{S}, 19^{\circ} \mathrm{W}-50^{\circ} \mathrm{E}\right)$ for ASO (i.e. $\Delta=$ EXPERIMENT-CTRL). In contrast to Figures 1 through 3, which evaluated the representativeness of the aerosol optical properties against observations, here we evaluate the sensitivity of the climate response over the region to the bb aerosol specifications. Because only the bb aerosol forcing differs between a given experiment and CTRL, analyzing these differences yields the response of the model to $b b$ forcing only, where here we have assumed that the $b b$ aerosol forcing is dominated by its carbonaceous (BC plus OC) component. Our equilibrium experiments are not appropriate to gain insight into the actual time evolution of the 20th century climate response to bb aerosols. This is because we do not consider transient changes in aerosols; our aerosols are constant and nominally representative of the present day. Since we are attempting to extract the influences of aerosols alone on observed climate changes, isolated from additional forcing factors such as GHGs, land-use change, and SSTs that are present in the real climate, we cannot make direct comparisons to observational data. Our aim in this study is to systematically compare and contrast the range in the consequences for climate response that perturbations in bb aerosol optical properties impart. Because we only consider direct and semi-direct aerosol effects, this study should be seen as a first-degree estimate of the impacts of bb aerosol on the region.

Area-averaged shortwave SFC, TOA, and ATM all-sky (cloudy plus clear) radiative forcing efficiencies, which are defined as the radiative forcing per unit AOD, are shown in Figure 4a. Despite slight differences in their horizontal (Fig. 1) and vertical distributions (see supplemental material) of aerosol optical properties, the forcing efficiencies for HIGHEX and SSAEX are quite similar on an area-averaged basis; as a result, the climate response is also similar for these two experiments. Abel et al. (2005) conducted an extensive sensitivity study of direct aerosol forcing over southern Africa, and the TOA and SFC forcing for SSAEX and HIGHEX is generally consistent with their forcing estimates for highly absorbing bb haze ( $\mathrm{SSA}=0.89$ ).

Figure $4 \mathrm{~b}$ shows the change, relative to CTRL, in the ASO area-average components of the land surface energy balance for each experiment. Positive (negative) terms warm (cool) the surface. The land surface energy balance is given by:

$S+F+L E+H \approx 0$ 
(a)

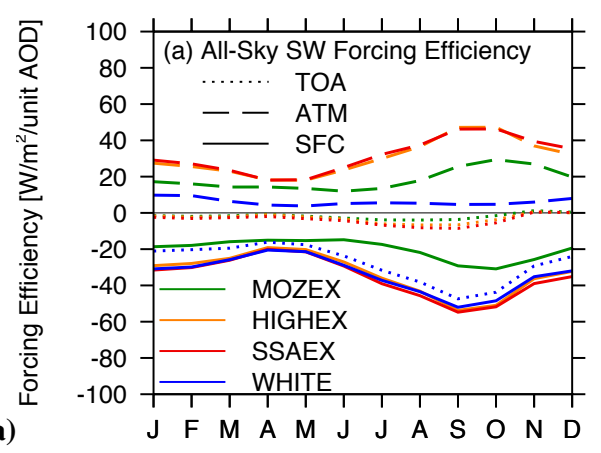

(b)

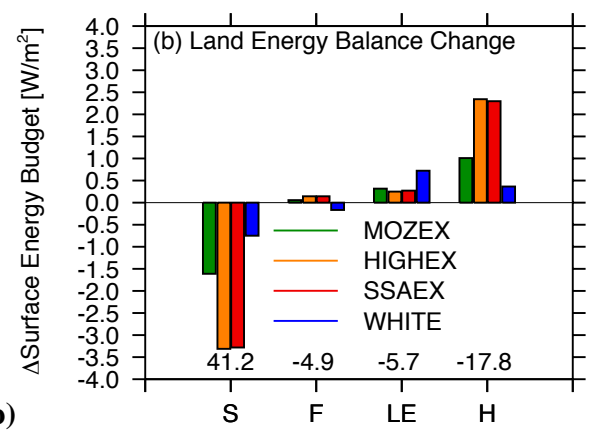

Fig. 4. (a) Monthly-mean area-averaged $\left(3^{\circ} \mathrm{N}-37^{\circ} \mathrm{S}, 19^{\circ} \mathrm{W}-\right.$ $50^{\circ} \mathrm{E}$ ) all-sky (cloudy) SFC, ATM, and TOA short-wave (SW) forcing efficiency $\left[\mathrm{W} \mathrm{m}^{-2}\right.$ per unit AOD], where TOA $=\mathrm{SFC}+\mathrm{ATM}$. (b) ASO area-average equilibrium change in $S, F, L E$, and $H$ fluxes at the surface relative to CTRL from Eq. (3) $\left[\mathrm{W} \mathrm{m}^{-2}\right]$; positive (negative) changes warm (cool) the surface. Area-average values for CTRL are listed along the lower portion of panel (b).

where $S$ is the net (down minus up) solar (shortwave) heat flux at the surface, $F$ is the net longwave heat flux, and $L E$ and $H$ are the net latent and sensible heat fluxes, respectively. Note that, while the balance in Equation (3) is obtained for the global, annual mean (not shown), there is a small residual for ASO. Absorbing bb burning aerosols (MOZEX, HIGHEX, SSAEX) decrease shortwave flux to the surface relative to CTRL, and increased (less negative) sensible heating rather than latent heating compensates this surface cooling due to the dryness of the season (Abel et al., 2005). In contrast, when scattering-only aerosols increase (WHITE), area-average shortwave surface heating decreases less relative to the other experiments due to decreases in cloud amount (see Fig. 6), and latent heating occurs as evaporation decreases (see Table 3).

Figure 5 shows the surface air temperature, total precipitation, 850-hPa winds, low level cloud distribution, and column-integrated water vapor for the CTRL experiment. The CTRL experiment climate is qualitatively consistent with observations and reanalysis data, which also include the effects of carbonaceous aerosols not considered in CTRL (see supplemental material). Figure 6 (a-d) shows the change in surface air temperature $\left(\Delta T_{\text {sat }}\right)$ and the change in lowlevel cloud amount for each experiment relative to CTRL.
BB aerosol backscattering and absorption reduce shortwave radiation at the surface, and significant cooling is observed in central Africa $\left(\sim 0-17^{\circ} \mathrm{S}\right.$ over land). The cooling pattern observed in MOZEX, SSAEX, and HIGHEX is spatially coherent with the pattern of bb aerosol AOD (Fig. 1), and both higher AOD and cloud amount increases in SSAEX and HIGHEX contribute to stronger surface air cooling over land compared to MOZEX. These low-level cloud increases amount to a negative semi-direct effect of bb aerosol. The combined influence of bb aerosols and clouds on surface air temperature serve to decrease the positive bias in surface air temperature between CTRL and observations (supplemental material). Conversely, decreased cloud amount in equatorial Africa in WHITE contributes to surface warming in this region despite high bb aerosol AOD. This contrasting effect of scattering-only aerosols highlights the important role of absorbing bb aerosol on modulating the surface air temperature response over land both directly through aerosol extinction and through changes in cloud distributions that occur due to aerosol heating (semi-direct effect).

Over the ocean, there is little change in surface air temperature for all experiments since SSTs are the same as in the CTRL experiment. However, when absorbing bb aerosol is increased, clouds tend to decrease over the ocean north of $10^{\circ} \mathrm{S}$ (where bb burning AOD is the highest) and increase to the south $\left(\sim 10^{\circ} \mathrm{S}-15^{\circ} \mathrm{S}\right)$. The zonally averaged air temperature change (not shown) indicates that the troposphere generally warms in MOZEX, HIGHEX, and SSAEX, though there is cooling near the land surface in the region with the highest bb aerosol AOD $\left(\sim 0-17^{\circ} \mathrm{S}\right)$, indicating an increase in low-level thermodynamic stability over land. The atmosphere generally cools throughout in WHITE, though there is some near-surface warming over land north of $10^{\circ} \mathrm{S}$, likely due to sensible and latent warming.

Figure 6e-h shows the change in precipitation $(\Delta P)$ and the change in column-integrated precipitable water vapor $(\triangle W V P)$ for each experiment relative to CTRL. Rainfall changes are small and generally not significant, except in WHITE where significant decreases occur in central equatorial Africa. We note that the stronger increases in absorbing bb aerosol in SSAEX and HIGHEX are associated with small regions of precipitation increase in central equatorial Africa. The rainfall anomaly patterns induced by bb aerosol over central Africa are consistent with the patterns of water vapor, which are more significant than the precipitation changes. Our cloud and water vapor changes in HIGHEX and SSAEX are consistent with a negative semi-direct effect.

Figure 7a-d shows the change in soil moisture for each experiment relative to control. Both MOZEX and HIGHEX indicate that soil moisture increases in equatorial southern Africa, consistent with the findings of Roeckner et al. (2006) and the positive bias relative to CTRL in the difference of precipitation minus evaporation $(\Delta(P-E)$; Fig. 7e-h). In contrast, SSAEX and WHITE primarily have decreases in soil moisture in the same region. The annual cycle of soil 

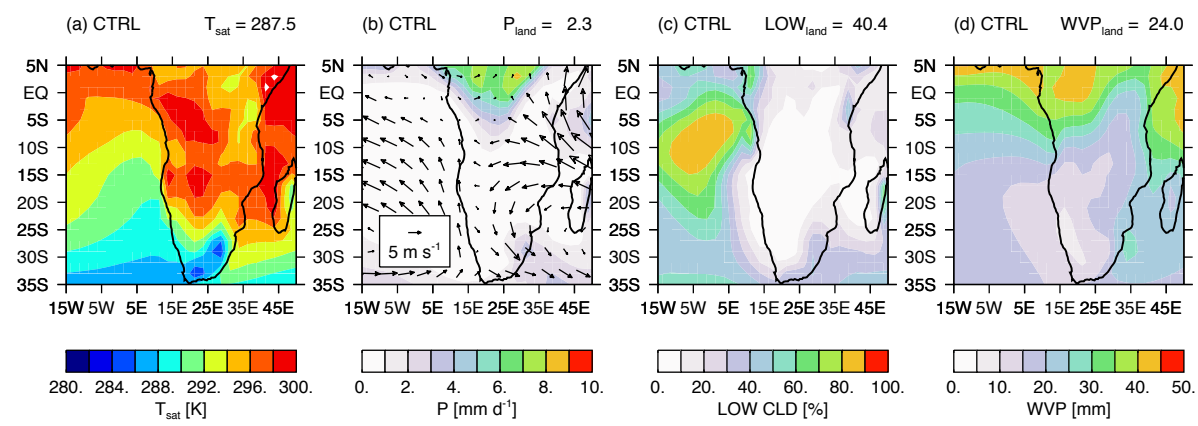

Fig. 5. CTRL case (a) surface air temperature $\left[T_{\mathrm{sat}} ; \mathrm{K}\right]$, (b) total precipitation $\left[\mathrm{P} ; \mathrm{mm} \mathrm{d}^{-1}\right]$ and $850-\mathrm{hPa}$ winds $\left[\mathrm{m} \mathrm{s}^{-1}\right]$, (c) low level cloud distribution [\%], and (d) column-integrated water vapor [WVP; mm] for ASO. See supplemental material for comparison of these figures to observations and reanalysis data.
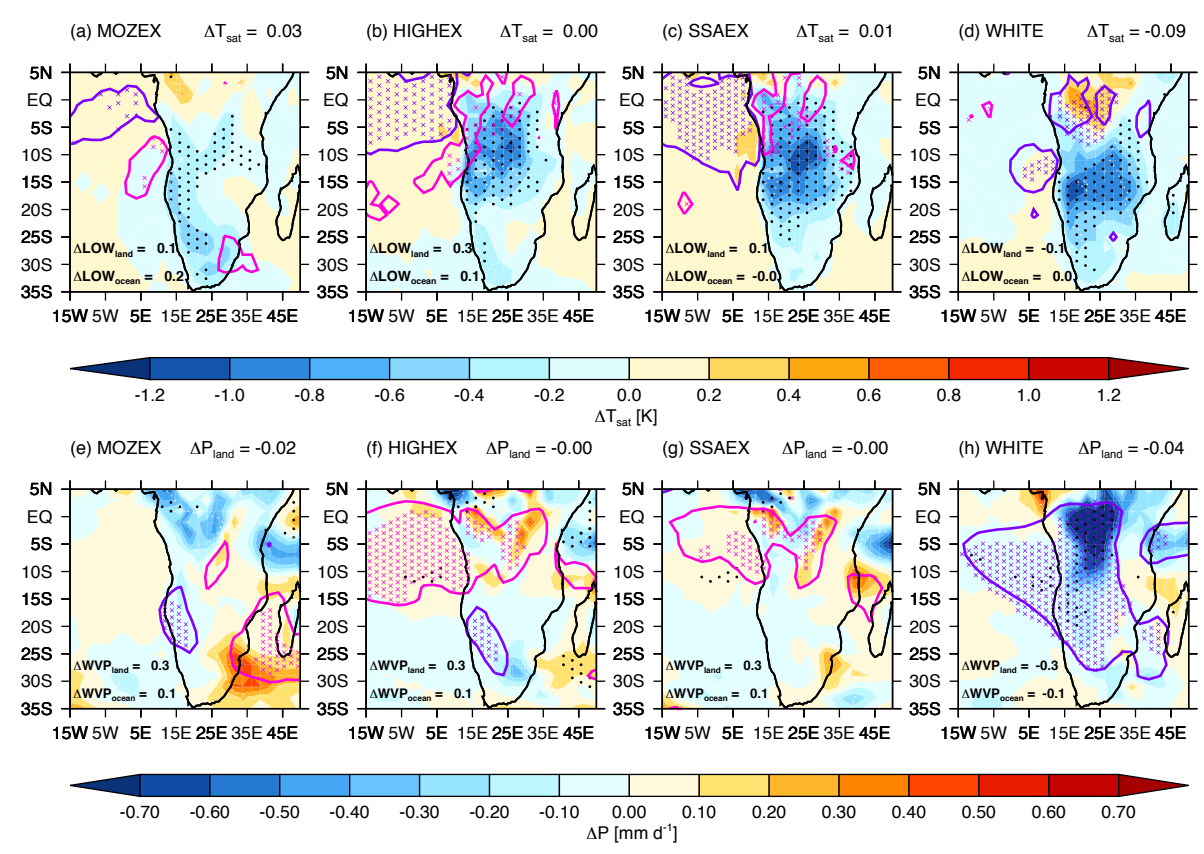

Fig. 6. ASO surface air temperature change relative to CTRL $\left(\Delta T_{\mathrm{sat}}\right.$; [K]) (shaded) for (a) MOZEX, (b) HIGHEX, (c) SSAEX, and (d) WHITE with black stippling indicating that changes are significant above $90 \%$. Overlain pink (purple) contours are increased (decreased) low-level cloud above (below) $2.5 \%$ with pink (purple) crosses denoting $90 \%$ significance. Change in total precipitation relative to CTRL $\left(\triangle P ;\left[\mathrm{mm} \mathrm{d}^{-1}\right]\right)$ (shaded) for (e) MOZEX, (f) HIGHEX, (g) SSAEX, and (h) WHITE with black stippling indicating $90 \%$ significance. Overlain pink (purple) contours are increased (decreased) column-integrated precipitable water $(\Delta \mathrm{WVP})$ above (below) $0.5 \mathrm{~mm}$ with pink (purple) crosses denoting $90 \%$ significance.

moisture change (supplemental material) shows that the evolution of soil moisture in SSAEX decreases throughout much of the year, as it does in WHITE, particularly in the main bb region $\left(7^{\circ} \mathrm{S}-17^{\circ} \mathrm{S}, 11^{\circ} \mathrm{E}-29^{\circ} \mathrm{E}\right)$. This is different from MOZEX and HIGHEX which both show increases in soil moisture throughout the year similar to the results of Roeckner et al. (2006). This may explain why the increases in precipitation in equatorial southern Africa are smaller for SSAEX compared to HIGHEX, as there is strong coupling between soil moisture and precipitation in this region (e.g. Koster et al., 2004).
During the dry season, a semi-permanent continental-scale subtropical anticyclone induces large-scale subsidence over southern Africa (Garstang et al., 1996). The ASO change in sea-level pressure (SLP) and $850-\mathrm{hPa}$ winds relative to CTRL is shown in Figure 8a-d. Increasing absorbing bb aerosol tends to increase low-level flow from the equatorial Atlantic towards the west African coast, and SLP increases over land when AOD is high (HIGHEX and SSAEX), consistent with the findings of Roeckner et al. (2006) and RR08. However, when there are strong increases in scattering aerosols only (WHITE), the 850-hPa wind anomaly is in 
Table 3. Summary of ASO area-weighted average $\left(3^{\circ} \mathrm{N}-37^{\circ} \mathrm{S}, 19^{\circ} \mathrm{W}-50^{\circ} \mathrm{E}\right)$ changes in surface air temperature $\left(T_{\mathrm{sat}}\right.$; K), precipitation minus evaporation $\left(P-E ;\left[\mathrm{mm} \mathrm{d}^{-1}\right]\right)$, column-integrated precipitable water vapor (WVP) [mm], low-level clouds [\%], and soil moisture $[\mathrm{mm}]$. Land-only averages are given with land plus ocean averages in parenthesis.

\begin{tabular}{lrrrr}
\hline Change Relative to CTRL & MOZEX & HIGHEX & SSAEX & WHITE \\
\hline$\Delta T_{\text {sat }}[\mathrm{K}]$ & $-0.12(-0.08)$ & $-0.27(-0.15)$ & $-0.35(-0.18)$ & $-0.27(-0.16)$ \\
$\Delta(P-E)\left[\mathrm{mm} \mathrm{d}^{-1}\right]$ & $+0.02(+0.04)$ & $+0.05(+0.08)$ & $+0.05(+0.08)$ & $-0.1(-0.07)$ \\
$\Delta$ Precipitable Water [mm] & $0(+0.1)$ & $+0.2(+0.3)$ & $+0.2(+0.2)$ & $-1.2(-0.9)$ \\
$\Delta$ Low Clouds [\%] & $+0.4(+0.4)$ & $+0.7(+0.1)$ & $+0.7(-0.3)$ & $-1.0(-0.9)$ \\
$\Delta$ Soil Moisture [mm] & +0.32 & +1.53 & -0.85 & -3.31 \\
\hline
\end{tabular}
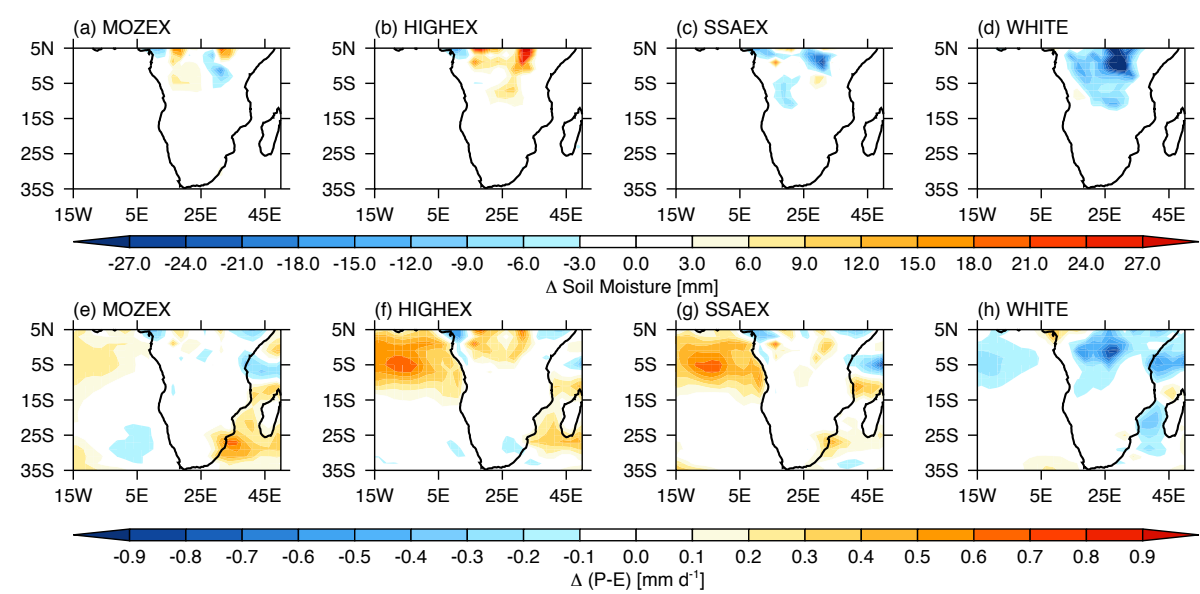

Fig. 7. ASO soil moisture change relative to CTRL ( $\Delta$ Soil Moisture; [mm]) for (a) MOZEX, (b) HIGHEX, (c) SSAEX, and (d) WHITE. ASO change in precipitation minus evaporation $\left(\Delta(\mathrm{P}-\mathrm{E}) ; \mathrm{mm} \mathrm{d}^{-1}\right)$ relative to CTRL for (e) MOZEX, (f) HIGHEX, (g) SSAEX, and (h) WHITE.

the same sense as the CTRL experiment (i.e. from land to ocean; Fig. 5).

The zonally-averaged circulation anomalies (Fig. 8e-h) indicate increased upward motion coincident with regions of increased absorbing bb aerosol $\left(\sim 0-17^{\circ} \mathrm{S}\right)$. This rising motion, along with the anomalous low-level circulation and subsequent low-level convergence (not shown) contribute to the simulated increases in column-integrated water vapor, precipitation, and clouds over land in SSAEX and HIGHEX (and, to a lesser extent in MOZEX). There are much weaker increases in vertical motion in equatorial Africa in WHITE, and increasing aerosol scattering alone tends to spin-down the hydrologic cycle in southern Africa. Table 3 summarizes the area-average changes in surface air temperature and the hydrologic cycle examined in this study.

\section{Discussion and conclusions}

Motivated by the variability in the observations of aerosol optical properties and the wide range in the estimates of aerosol radiative forcing over southern Africa, simulations are carried out in the GFDL AM2-LM2 GCM to test the cli- mate sensitivity to a range of biomass burning aerosol optical properties. The modeled direct and semi-direct effects of absorbing bb aerosol reduce the solar flux to the surface (both through aerosol extinction and cloud increases), heat the atmosphere, and tend to stabilize the troposphere below the aerosol layer over land in the main biomass burning region while increasing the surface pressure. Over the ocean, however, the cooling tendency of this reduced solar flux is not realized (due to prescribed SSTs in this case, or, alternatively due to a lagged ocean response), though bb aerosol absorption still exerts a warming tendency on the atmosphere, thus destabilizing the column over the ocean. A thermallydriven anomalous circulation from the western Atlantic towards the west African coast results, and warm, moist air is lofted above the continent, increasing clouds, water vapor, and, to a lesser extent, precipitation in the main bb aerosol region $\left(\sim 0-17^{\circ} \mathrm{S}\right)$.

We also consider a case in which bb aerosols are completely scattering, and this experiment represents a hypothetical case, at least in the context of the contemporary atmosphere. This experiment serves to flush out the contrasts in the response to scattering aerosols, which only exert a 

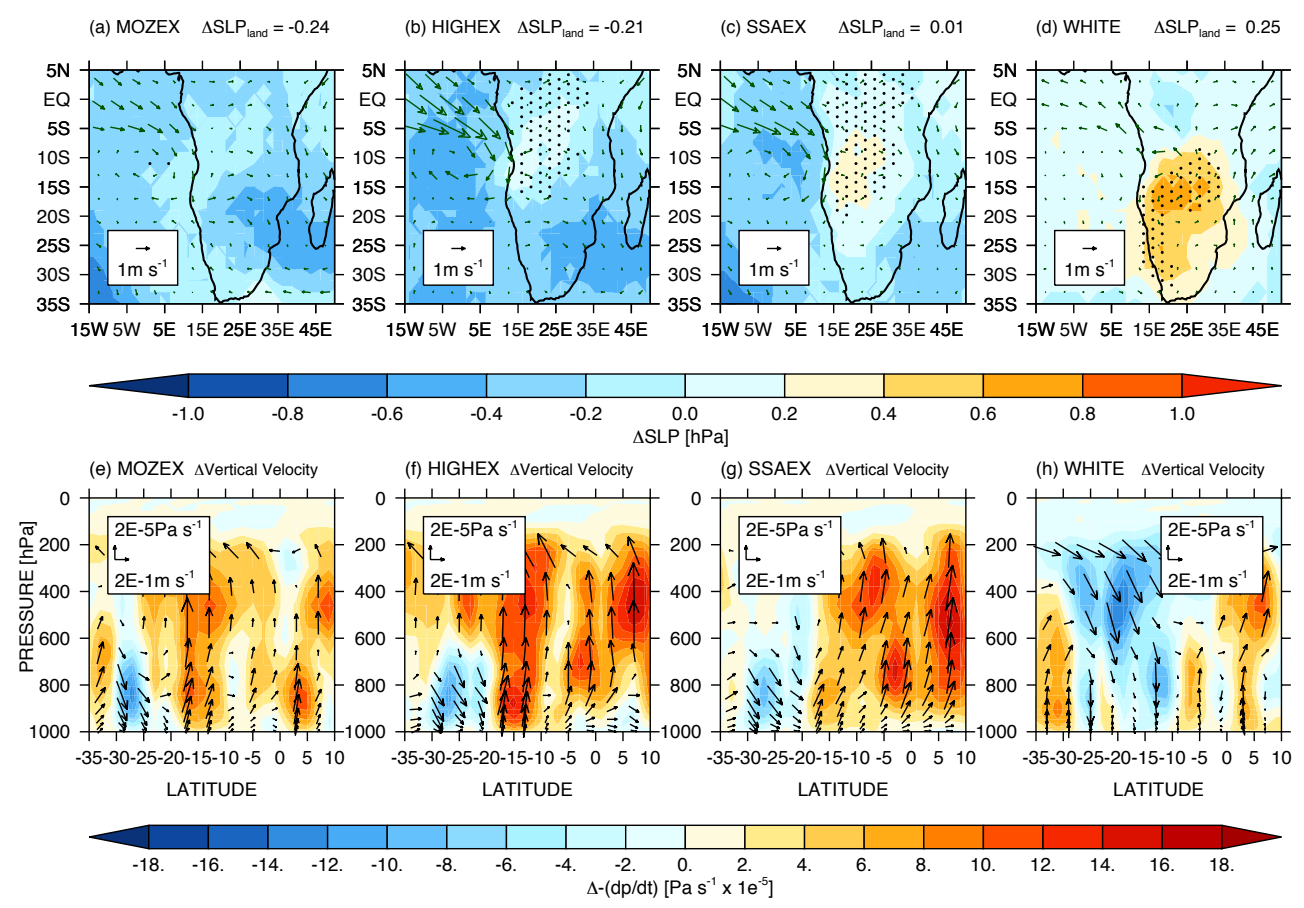

Fig. 8. ASO change in sea level pressure $(\triangle \mathrm{SLP})$ relative to CTRL $[\mathrm{hPa}]$ for (a) MOZEX, (b) HIGHEX, (c) SSAEX, and (d) WHITE overlain with $850-\mathrm{hPa}$ wind anomaly $\left[\mathrm{mm} \mathrm{d}^{-1}\right]$ relative to CTRL; black stippling represents $\triangle$ SLP above $90 \%$ significant. Zonally averaged $\left(0-50^{\circ} \mathrm{E}\right)$ change in vertical velocity $(-d p / d t)$ relative to CTRL $\left[\mathrm{Pa} \mathrm{s}^{-1} \times 1 \mathrm{e}^{-5}\right]$ for (e) MOZEX, (f) HIGHEX, (g) SSAEX, and (h) WHITE overlain with meridional circulation change; note red (blue) shading indicates increased upward motion (relative subsidence).

radiative cooling tendency on the surface, with the response to absorbing aerosols, which simultaneously cool the surface and warm the atmosphere. Our results show that increased aerosol scattering in the absence of increased absorption tends to cool the atmosphere over southern Africa and enhance subsidence over the region. Importantly, the resulting decreases in cloud amount offset some of the surface cooling tendency associated with high aerosol extinction, and the hydrologic cycle over southern Africa tends to spin-down compared to increasing absorbing bb aerosol.

In this study, SSTs were prescribed as an important first step to isolate and examine only the effects of aerosols on southern Africa without the complexity of a fully coupled ocean-atmosphere model. By applying observed SSTs as the lower boundary condition, we remove much of the uncertainty in the lower-boundary forcing that may be derived from use of a mixed-layer ocean or a fully coupled ocean model. However, it is important to note that if SST changes due to aerosol surface cooling were to yield strong feedbacks, particularly with regard to clouds, the effects of aerosols on the hydrologic cycle could become more complicated. For example, cooler SSTs due to increased aerosol loadings may contribute to decreases in surface convergence (e.g. Hackert and Hastenrath, 1986) and convection; however, the SST response is expected to lag aerosol forcing (e.g. Ramanathan and Carmichael, 2008). While we ac- knowledge that future studies of the direct and semi-direct effects of biomass burning aerosols on this region should consider ocean-atmosphere feedbacks, we hold that atmosphereonly simulations remain useful tools from which we can gain an initial understanding of the climate response to aerosol forcing. We also are given confidence in our results for the climate response to HIGHEX and SSAEX because they are qualitatively consistent with the findings of Roeckner et al. (2006), which used a fully coupled atmosphere-ocean model, interactive aerosols, and the first (Twomey) aerosol indirect effect. Our findings with regard to the direct and semi-direct effects of bb aerosols on the hydrologic cycle are also broadly consistent with the findings of Ott et al. (2009), which studied the climate effects of biomass burning in the Indonesian region.

Our findings may also be sensitive to the GCM convective parameterization (e.g. Chakraborty et al., 2004), as we have shown that dynamically driven cloud changes can reinforce or eclipse aerosol effects, particularly on surface air temperature. Inclusion of aerosol indirect effects would also complicate the relationship between aerosols and cloud amount and their associated surface solar flux changes. However, global-model representations of the first (Twomey) and second (Albrecht) indirect effects remain primitive, and given the dryness of the region in austral winter, we expect the aerosol direct and semi-direct effects to dominate in southern 
Africa. We also neglected the feedback of the hydrologic cycle on aerosol distributions; however, we again expect this to be rather small during the dry season studied here. We note that our most absorbing cases (HIGHEX and SSAEX) may underestimate aerosol absorption over southern Africa; stronger aerosol absorption would likely strengthen both the dynamic and hydrodynamic responses observed in these experiments. This is indicated by differences in the response of SSAEX compared to HIGEX, the latter of which is slightly more absorbing.

Despite these caveats, our study supports the primary conclusion that the direct and semi-direct effects of biomass burning aerosol are important players in climate change over southern Africa. In particular, it is clear that the hydrologic cycle over the continent is sensitive to the total amount of aerosol absorption, and that the semi-direct effect of absorbing aerosols on cloud distributions can reinforce the cooling effect of aerosol extinction on the surface air temperature as aerosol absorption optical depth increases.

\section{Supplement related to this article is available online at: http://www.atmos-chem-phys.net/10/9819/2010/ acp-10-9819-2010-supplement.pdf.}

Acknowledgements. The authors thank Paul Ginoux and Hiram Levy II for thoughtful comments on the manuscript. We thank Omar Torres for providing daily EP-TOMS retrievals of AOD and SSA for 2000 and the AERONET investigators and their staff for establishing and maintaining the 18 sites used in this investigation. We also thank the four anonymous reviewers for their constructive comments that have improved this work. CAR acknowledges funding from the Department of Energy (DOE) Graduate Research Environmental Fellowship (GREF) and the Princeton AOS program.

Edited by: D. Shindell

\section{References}

Abel, S. J., Highwood, E. J., Haywood, J. M., and Stringer, M. A.: The direct radiative effect of biomass burning aerosols over southern Africa, Atmos. Chem. Phys., 5, 1999-2018, doi:10.5194/acp-5-1999-2005, 2005.

Anderson, J., Balaji, V., Broccoli, A. J., et al.: The new GFDL global atmosphere and land model AM2-LM2: Evaluation with prescribed SST simulations, J. Climate, 17, 4641-4673, 2004.

Brioude, J., Cooper, O. R., Feingold, G. Trainer, M., Freitas, S. R., Kowal, D. Ayers, J. K., Prins, E., Minnis, P., McKeen, S. A., Frost, G. J., and Hsie, E.-Y.: Effect of biomass burning on marine stratocumulus clouds off the California coast, Atmos. Chem. Phys., 9, 22, 8841-8856, doi:10.5194/acp-8-8841-2009, 2009.

Chakraborty, A., Satheesh, S. K., Nanjundiah, R. S., and Srinivasan, J.: Impact of absorbing aerosols on the simulation of climate over the Indian region in an atmospheric general circulation model, Ann. Geophys., 22, 1421-1434, doi:10.5194/angeo-221421-2004, 2004.
Chýlek, P. and Coakley, J. A.: Aerosols and Climate, Science, 183, 75-77, 1974

Delworth, T. L., Broccoli, A. J., Rosati, A., et al.: GFDL's CM2 global coupled climate models- Part 1: Formulation and simulation characteristics, J. Climate, 19(5), 643-674, 2006.

Garstang, M., Tyson, P. D., Swap, R., Edwards, M., Kållbert, P., and Lindesay, J. A.: Horizontal and vertical transport of air over southern Africa, J. Geophys. Res., 101, 23721-23736, 1996.

Ginoux, P., Horowitz, L. W., Ramaswamy, V., Geogdzhayev, I. V., Holben, B. N., Stenchikov, G., and Tie, X.: Evaluation of aerosol distribution and optical depth in the Geophysical Fluid Dynamics Laboratory coupled model CM2.1 for present climate, J. Geophys. Res., 111, D22210, doi:10.1029/2005JD006707, 2006.

Hackert, E. C. and Hastenrath, S.: Mechanisms of Java rainfall anomalies, Mon. Weather Rev., 114, 745-757, 1986.

Hansen, J., Sato, M., and Ruedy, R.: Radiative forcing and climate response, Journal of Geophysical Research, 102(D6), 68316864, 1997.

Haywood, J. M. and Ramaswamy, V.: Global Sensitivity studies of the direct radiative forcing due to anthropogenic sulfate and black carbon aerosols, J. Geophys. Res., 103(D6), 6043-6058, 1998.

Haywood, J. M., Ramaswamy, V., and Soden, B. J.: Tropospheric aerosol climate forcing in clear-sky satellite observations over the oceans, Science, 283, 5406, 1299-1303, 1999.

Haywood, J. M., Osborne, S. R., Francis, P. N., Keil, A., Formenti, P., Andreae, M. O., and Kaye, P. H.: The mean physical and optical properties of regional haze dominated by biomass burning aerosol measured from the C-130 aircraft during SAFARI 2000, J. Geophys. Res., 108(D13), 8473, doi:10.1029/2002JD002226, 2003.

Holben, B., Tanre, D., Smirnov, A., et al.: An emerging ground-based aerosol climatology: Aerosol optical depth from AERONET, J. Geophys. Res., 106(D11), 12067-12097, 2001.

Horowitz, L.: Past, present, and future concentrations of tropospheric ozone and aerosols: Methodology, ozone evaluation, and sensitivity to aerosol wet removal, J. Geophys. Res., 111, D22211, doi:10.1029/2005JD006937, 2006.

Johnson, B. T., Shine, K. P., and Forster, P. M.: The semi-direct aerosol effect: Impact of absorbing aerosols on marine stratocumulus, Q. J. Roy. Meterol. Soc., 130(599), 1407-1422, 2004.

Kaufman, Y. J., Tanre, D., Remer, L., Vermonte, E., Chu, A., and Holben, B. N.: Remote sensing of tropospheric aerosol over the land using dark targets and dynamic aerosol models,J. Geophys. Res., 102, 17051-17067, 1997.

Keil, A. and Haywood, J. M.: Solar radiative forcing by biomass burning aerosol particles during SAFARI 2000: A case study based on measured aerosol and cloud properties, J. Geophys. Res., 108(D13), 8467, doi:10.1029/2002JD002315, 2003.

Koch, D. and Del Genio, A. D.: Black carbon semi-direct effects on cloud cover: review and synthesis, Atmos. Chem. Phys., 10, 7685-7696, doi:10.5194/acp-10-7685-2010, 2010.

Koch, D., Schulz, M., Kinne, S., McNaughton, C., Spackman, J. R., Balkanski, Y., Bauer, S., Berntsen, T., Bond, T. C., Boucher, O., Chin, M., Clarke, A., De Luca, N., Dentener, F., Diehl, T., Dubovik, O., Easter, R., Fahey, D. W., Feichter, J., Fillmore, D., Freitag, S., Ghan, S., Ginoux, P., Gong, S., Horowitz, L., Iversen, T., Kirkevåg, A., Klimont, Z., Kondo, Y., Krol, M., Liu, X., Miller, R., Montanaro, V., Moteki, N., Myhre, G., Penner, J. E., 
Perlwitz, J., Pitari, G., Reddy, S., Sahu, L., Sakamoto, H., Schuster, G., Schwarz, J. P., Seland, Ø., Stier, P., Takegawa, N., Takemura, T., Textor, C., van Aardenne, J. A., and Zhao, Y.: Evaluation of black carbon estimations in global aerosol models, Atmos. Chem. Phys., 9, 9001-9026, doi:10.5194/acp-9-9001-2009, 2009.

Koren, I., Kaufman, Y. J., Remer, L. A., and Martins, J. V.: Measurement of the effect of Amazon smoke on inhibation of cloud formation, Science, 303, 1342-1345, doi:10.1126/science.1089424, 2004.

Koster, R. D., Suarez, M. J., Liu, P., et. al.: Regions of strong coupling between soil moisture and precipitation, Science, 305, 1138-1140, 2004.

Lau, K. M., Kim, K. M., Sud, Y. C., and Walker, G. K.: A GCM study of the response of the atmospheric water cycle of West Africa an the Atlantic to Saharan dust radiative forcing, Ann. Geophys., 27, 4023-4037, doi:10.5194/angeo-27-40232009, 2009.

Lau, K. M., Kim, M. K., and Kim, K. M.: Asian summer monsoon anomalies induced by aerosol direct forcing: The role of the Tibetan Plateau, Clim. Dynam., 26(7-8), 855-864, 2006.

Leahy, L. V., Anderson, T. L., Eck, T. F., and Bergstrom, R. W.: A Synthesis of biomass burning aerosol over southern Africa during SAFARI 2000, Geophys. Res. Lett., 34, L12814, doi:10.1029/2007GL029697, 2007.

Magi, B.: Chemical apportionment of southern African aerosol mass and optical depth, Atmos. Chem. Phys., 9, 7643-7655, doi:10.5194/acp-9-7643-2009, 2009.

Magi, B. I., Ginoux, P., Ming, Y., and Ramaswamy, V.: Evaluation of tropical and extratropical Southern Hemisphere African aerosol properties simulated by a climate model, J. Geophys. Res., 114, D14204, doi:10.1029/2008JD011128, 2009.

Magi, B. I. and Hobbs, P. V.: Hobbs: Effects of humidity on aerosols in southern Africa during the biomass burning season, J. Geophys. Res., 108(D13), 8495, doi:10.1029/2002JD002144, 2003.

Menon, S., Hansen, J., Nazarenko, L., and Luo, Y.: Climate effects of black carbon aerosols in China and India, Science, 297, 22502253, 2002.

Miller, R. L., Tegen, I., and Perlwitz, J.: Surface radiative forcing by soil dust aerosols and the hydrologic cycle, J. Geophys. Res., 109, D04203, doi:10.1029/2003JD004085, 2004.

Ming, Y., Ramaswamy, V., Ginoux, P. A., and Horowitz, L. H.: Direct radiative forcing of anthropogenic organic aerosol, J. Geophys. Res., 110, D20208, doi:10.1029/2004JD005573, 2005.

Myhre, G., Bernsten, T. K., Haywood, J. M., Sundet, J. K., Holben, B. N., Johnsrud, M., and Stordal, F.: Modeling the solar radiative impact of aerosols from biomass burning during the Southern African Regional Science Initiative (SAFARI-2000) experiment, J. Geophys. Res., 108(D13), 8501, doi:10.1029/2002JD002313, 2003.
Ott, L., Duncan, B., Pawson, S., Colarco, P. R., Chin, M., Randles, C., Diehl, T., and Nielsen, E.: The influence of the 2006 Indonesian biomass burning aerosols on tropical dynamics studied with the GEOS-5 AGCM, J. Geophys. Res., doi:10.1029/2009JD013181, D14121, 2010.

Paeth, H. and Feichter, J: Greenhouse-gas versus aerosol forcing and African climate response, Clim. Dynam., 26, 35-54, 2006.

Ramanathan V. and Carmichael, G.: Global and regional climate changes due to black carbon, Nat. Geosci., 1, 221-227, 2008.

Ramanathan, V., Chung, C., Kim, D., Bettge, T., Buja, L., Kiehl, J. T., Washington, W. M., Fu, Q., Sikka, D. R., and Wild, M.: Atmospheric brown clouds: Impacts on South Asian climate and hydrological cycle, P. Natl. Acad. Sci., 102, 15, 5326-5333, 2005.

Randles, C. A. and Ramaswamy, V.: Absorbing aerosols over Asia: A GFDL general circulation model sensitivity study of model response to aerosol optical depth and aerosol absorption, J. Geophys. Res., 113, D21203, doi:10.1029/2008JD010140, 2008.

Reynolds, R. W., Rayner, N. A., Smith, T. M., Stockes, D. C., and Wang, W.: An improved in situ and satellite SST analysis for climate, J. Climate, 15, 1609-1625, 2002.

Roeckner, E., Stier, P., Feichter, J., Kloster, S., Esch, M., and Fischer-Bruns, L.: Impact of carbonaceous aerosol emissions on regional climate change, Clim. Dynam., 27, 552-571, 2006.

Solomon S., Qin, D., Manning, M., et al.: Technical Summary Contribution of Working Group 1 to the 4th Assessment Report of the Intergovernmental Panel on Climate Change, in: Climate Change 2007: The Physical Science Basis, Cambridge University Press, New York, USA, 21-87, 2007.

Swap, R. J., Annegarn, H. J., Suttles, J. T., King, M. D., Platnick, S., Privette, J. L., and Scholes, R. J.: Africa burning: A thematic analysis of the Southern African Regional Science Initiative (SAFARI 2000), J. Geophys. Res., 108(D13), 8465, doi:10.1029/2003JD003747, 2003.

Torres, O., Bhartia, P. K., Herman, J. R., Ahmad, Z., and Gleason, $\mathrm{J}$.: Derivation of aerosol properties from satellite measurements of backscattered ultraviolet radiation: Theoretical basis, J. Geophys. Res., 103, 17099-17110, 1998.

Torres, O., Bhartia, P. K., Herman, J. R., Syniuk, A., Ginoux, P., and Holben, B.: A long-term record of aerosol optical depth from TOMS observations and comparison to AERONET measurements, J. Atmos. Science, 59, 398-413, 2002.

Torres, O., Bhartia, P. K., Sinyuk, a., Welton, E. J., and Holben, B.: Total Ozone Mapping Spectrometer measurements of aerosol absorption from space: Comparison to SAFARI 2000 ground-based observations, J. Geophys. Res., 110, D10S18, doi:10.1029/2004JD004611, 2005. 